\title{
A educação a distância como instrumento de democratização do ensino: uma estudo de caso na Amazônia Brasileira
}

\section{La educación a distancia como herramienta de enseñanza democratización: un estudio de caso en la Amazonia brasileña}

\section{Distance Education as a teaching democratization tool: a case study in the Brazilian Amazon}

\author{
Adriana De Moura* \\ Fatima Gonçalves Cavalcante* \\ Fecha de recepción: 21 de julio de 2016 \\ Fecha de evaluación: 15 de marzo de 2017 \\ Fecha de aceptación: 8 de mayo de 2017 \\ Disponible en línea: 18 de mayo de 2017
}

DOI: http://dx.doi.org/10.18359/reds.2012

Cómo citar este artículo:

Moura, A. de y Gonçalves Cavalcante, F. (2017). A educação a distância como instrumento de democratização do ensino: uma estudo de caso na Amazônia Brasileira. Revista Educación y Desarrollo Social, 11(1), 102-115. DOI: http://dx.doi.org/10.18359/reds.2012

Psicóloga; Master en Psicoanálisis, Salud y Sociedad, de la Universidad Veiga de Almeida/ Rio de Janeiro, Brasil. Correo electrónico: adrimourapan@gmail.com

** Psicólogo; Post-doctorado en Salud Pública y Antropología Social. Profesor de la Universidad Veiga de Almeida/ Rio de Janeiro, Brasil. Correo electrónico: fatimagold7x7@yahoo.com.br 


\section{Resumo}

Este artigo analisa uma experiência de educação à distância (EAD) promovida pela Universidade Aberta do Brasil (UAB), que graduou moradores de cidades ribeirinhas do Pará/Amazônia, isoladas do ponto de vista geográfico e social. O estudo buscou compreender a percepção de alunos e professores sobre a formação superior em licenciatura na modalidade EAD e sua relevância social. Foi feita uma investigação exploratória e qualitativa, na forma de estudo de caso, através de nove entrevistas semi-dirigidas e observação etnográfica. Os resultados indicam o sucesso do curso, em que pese a existência de barreiras tecnológicas e regionais. O limite está na sustentabilidade e continuidade dessas ações afirmativas que democratizam o ensino num país com tantas desigualdades educacionais e regionais como o Brasil.

Palavras-chave: educação à distância, universidade, cidades ribeirinhas, professor, aluno.

\section{Resumen}

En este artículo se analiza una experiencia de educación a distancia (EAD), organizado por la Universidad Abierta de Brasil (UAB), que se graduó de residentes de poblados ribereños de Pará / Amazon, aislado punto de vista geográfico y social. El estudio trata de comprender la percepción de los estudiantes y profesores sobre la educación superior en grado, de la modalidad de educación a distancia y su relevancia social. Se realizó una investigación exploratoria y cualitativa en forma de estudio de caso, a través de nueve entrevistas semiestructuradas y observación etnográfica. Los resultados indican el éxito del curso, a pesar de la existencia de barreras tecnológicas y regionales. El límite es la sostenibilidad y la continuidad de la acción afirmativa para la democratización de la educación en un país con tantas desigualdades educativas y regionales como Brasil.

Palabras clave: educación a distancia, universidad, ciudades ribereñas, profesor, estudiante.

\section{Abstract}

This article analyzes an experience of a distance education (DE) organized by the Open University of Brazil (OUB), who graduated residents of riverside towns of Pará/Amazonia, geographically and socially isolated. The study sought to understand the perception of students and teachers about the higher learning in distance education mode and its social relevance. It was done an exploratory and qualitative research, based in case study, through nine semi-structured interviews and ethnographic observation. The results indicated the success of the course, in despite of the existence of technological and regional barriers. The limit is the sustainability and continuity of these affirmative actions, that democratize education in a country with so many educational and regional inequalities as Brazil.

Keywords: distance education, university, riverside towns, teacher, student. 


\section{Introdução}

$\mathrm{O}$ artigo analisa uma experiência de educação à distância (EAD), ligada ao Sistema Universidade Aberta do Brasil (UAB), que viabiliza acesso universitário a comunidades ribeirinhas da Amazônia, submetidas a um forte isolamento geográfico e social. Sem contato com instituições de ensino superior, cujas bases estão distantes, observa-se restrição nos níveis de escolarização dessas populações, o que limita o desenvolvimento da região (Silva e Talamoni, 2008).

A expansão do acesso à educação é uma necessidade premente, do ponto de vista econômico e social, para melhorar a qualidade da mão de obra e tornar os produtos e serviços mais competitivos, mas também para a formação do cidadão, estimulando uma postura reflexiva e crítica, diante das demandas profissionais e dos acontecimentos do mundo.

O Sistema UAB integra universidades públicas e, por meio da EAD, oferece cursos de nível superior para camadas da população com dificuldades de acesso à formação universitária. Nesse sistema, a prioridade é formar professores que atuam na educação básica, seguidos de dirigentes e gestores em educação dos estados, municípios e do Distrito Federal. Tem finalidade de expandir e interiorizar a oferta de cursos e programas de educação superior no Brasil (Ministério da

104 Educação [MEC], 2014). As atividades da UAB no norte e nordeste ajudam a minimizar as desigualdades sociais e regionais.
O debate sobre a ampliação do ensino superior é relevante no mundo. Em 2009, a conferência da Unesco, em Paris, World Conference on Higlher Education, que contou com a participação de 150 países, discutiu a priorização de políticas que ampliem o acesso ao ensino superior, visando a garantia de qualidade e equidade na educação. Em 2014, o relatório da Organização para a Cooperação e o Desenvolvimento Econômico (OCDE) apontou que entre 36 países pesquisados, o Brasil é o que apresenta a maior diferença em termos de emprego e renda. O relatório mostra que um adulto com idade entre $25 \mathrm{e}$ 64 anos que termina o ensino superior receberá em média $157 \%$ mais do que quem só terminou o nível médio.

No Brasil, o Plano Nacional de Educação, de 2001 a 2010, aprovado pela lei $\mathrm{n}^{\circ} 10.172$, traz um diagnóstico dos indicadores do ensino superior entre os países da América Latina. O Brasil apresentou o mais baixo resultado, pois apenas $12 \%$ da população entre 18 e 24 anos tiveram acesso à Educação Superior, enquanto o Chile e a Bolívia atingiam 20,6\%; a Venezuela, $26 \%$; e a Argentina, $40 \%$ (Souza, 2007).

Walternberg (2005) aponta que os estudantes brasileiros apresentam o desempenho médio mais baixo, em todas as provas, entre os países avaliados no exame do Programa Internacional de Avaliação de Estudantes (PISA), com grande desigualdade entre os alunos considerados mais preparados e os menos preparados no país. O alto grau de 
iniquidade na educação básica, que afeta o ensino superior, tem raízes em profundas desigualdades sociais. Segundo relatório da Fórum Nacional de Educação (FNE) (2013), 47,1\% dos $20 \%$ de indivíduos com maior renda têm acesso ou já concluíram o ensino superior, enquanto apenas 4,2\% dos $20 \%$ de indivíduos com menor renda conseguiram acesso.

\section{Dados do Censo da Educação Superior} no Brasil, organizados pelo Instituto Nacional de Pesquisas Educacionais Anísio Teixeira [INEP] (2012) indicaram aumento de estudantes entre $18 \mathrm{e}$ 24 anos, entre 1997 e 2011 (de 7,1 \% para $17,6 \%$ ), em proporção inferior aos $40 \%$ planejados nessa faixa etária (FNE, 2014). De outro lado, O Censo do Instituto Brasileiro de Geografia e Estatística [IBGE] (2010), indicou que $49 \%$ da população adulta, com mais de 25 anos, não completou o ensino fundamental. No que diz respeito aos jovens que têm acesso ao ensino superior, existe uma disparidade entre os mais pobres e os mais ricos; entre brancos e não brancos; entre os que residem nos estados do norte e do nordeste e os que residem nas demais regiões do país, sendo muito mais difícil o acesso ao ensino superior para o jovem pobre, não branco, residente no norte ou nordeste do Brasil (FNE, 2014).

Esse cenário justifica o desenvolvimento de ações afirmativas, como as cotas sociais e raciais para acesso diferenciado ao ensino superior, o incremento do financiamento das instituições de ensino federais, a reestruturação do financiamento da educação superior privada com a aprovação e efetivação do programa universidade para todos (ProUni); o aperfeiçoamento do fundo de financiamento ao estudante do ensino superior (FIES), e a criação em 2006, por meio do Decreto $n^{0} 5.800$, do sistema UAB, direcionada à expansão e interiorização de cursos e programas por meio da educação a distância no país (FNE, 2014).

A EAD pode ser um meio de ampliação de acesso ao ensino superior. Para Preti (2009), o modelo tradicional tem se apresentado incapaz de atender às necessidades diversificadas e dinâmicas de educação e formação de adultos. A EAD pressupõe a otimização não só do atendimento aos alunos, mas também da oferta de vagas sem a instalação de grandes estruturas físicas e organizacionais, numa boa relação de custo-benefício. Para o autor, a maioria dos alunos que recorrem à EAD está inserido no mercado de trabalho, reside em locais distantes dos núcleos de ensino, não consegue aprovação em cursos regulares ou têm pouco tempo para estudar no ensino presencial. No Brasil, a EAD tem atendido a adultos que não tiveram oportunidade de estudar quando jovens, com média de 30 anos, a metade dos estudantes são pais e mães de família, que ganham até três salários mínimos, uma população trabalhadora, pobre $e$ em busca de melhores oportunidades (Valente e Moran, 2011).

$\mathrm{O}$ acesso ao ensino acadêmico, por intermédio da EAD, em regiões isoladas 
pelas distâncias físicas e socioculturais, como as cidades ribeirinhas da Amazônia, pode alavancar o desenvolvimento dos indivíduos e das comunidades, viabilizando a educação de pessoas nos próprios locais onde vivem. A maioria dos núcleos urbanos da Amazônia que margeiam a beira de rios, dedicam-se a atividades rurais, como agricultura familiar, pesca, e extrativismo, sendo a extração do açaí, a maior fonte de renda (Oliveira, 2004). O ensino superior pode ampliar e diversificar as atividades e o progresso local.

Este artigo tem como objetivo analisar a experiência da Universidade Aberta do Brasil numa cidade ribeirinha do Pará, visando compreender a percepção sobre a formação superior em licenciatura na modalidade EAD, na visão de alunos e professores. O estudo parte da dissertação de mestrado de Moura (2015) e analisa o acesso ao ensino superior na região da Amazônia, onde professores e alunos são protagonistas de uma educação que desafia barreiras físicas e sociais, com apoio de universidade pública e das políticas de interiorização do ensino superior no norte e nordeste do Brasil.

\section{Percurso metodológico}

\section{Desenho do estudo}

Foi feita uma pesquisa qualitativa ex106 ploratória com objetivo de conhecer a vivência de alunos e professores sobre sua graduação em licenciatura na modalidade EAD, no município São Sebastião da Boa Vista, destacando os impactos dessa experiência para os participantes. De acordo com Minayo (2001), a pesquisa qualitativa se preocupa com um nível de realidade que não pode ser quantificado, ou seja, trabalha com o universo de significados, motivos, aspirações, crenças, valores e atitudes, o que corresponde a um espaço mais profundo das relações, dos processos e dos fenômenos.

Foi realizado um estudo de caso, através de pesquisa de cunho etnográfico (Guimarães de Mattos, 2011). Para Moreira (1990), na pesquisa etnográfica existe a preocupação de se compreender o fenômeno social segundo a perspectiva dos atores, e isso é possível quando o pesquisador pode ficar imerso no fenômeno de interesse, por meio da participação na vida desses atores. Ao apreender as perspectivas dos participantes, a investigação participante permite a elucidação da dinâmica interna das situações que dificilmente são detectáveis pelo observador externo (Bogdan e Bïklen, 1994).

\section{Contexto e sujeitos da investigação}

O cenário do estudo é o município de São Sebastião de Boa Vista (SSBV), localizado no Estado do Pará, na zona do Marajó e Ilhas, sendo conhecido como a "Veneza do Marajó", por causa dos rios que cortam a cidade e são utilizados como vias de acesso para trafegar pelo interior do município. O Polo Veneza do Marajó, da UAB é a única fonte de acesso à graduação, no município. 
São Sebastião da Boa Vista, no censo de 2010, apresentava população residente de 22.904 habitantes, sendo 15.644 alfabetizados. Contava com 1025 crianças matriculadas na pré-escola; 5.978 alunos no ensino fundamental; e 871 no ensino médio, todos em escola pública, não havendo escolas particulares e estabelecimentos de ensino superior (IBGE, 2014).

Foram incluídos alunos que concluíram cursos de licenciatura, nas graduações de Pedagogia e Biologia, na modalidade EAD, realizada através da parceria UAB e Universidade do Estado do Pará (UEPA), que residiam no município de SSBV ou em localidades próximas. A exclusão foi pela distância, pois muitos eram de outros municípios, que implicavam em viagens de até nove horas de barco. Participaram do estudo sete ex-alunos dos cursos de licenciatura e dois professores de EAD, do Polo Veneza do Marajó.

\section{O Curso EAD no Polo Veneza do Marajó} era semipresencial, com aulas presenciais aos finais de semana, sendo condição fundamental para o bom andamento do curso, o acesso à plataforma durante a semana, para retirar material, tirar dúvidas e postar trabalhos. Esse modelo EAD é preconizado pelo Ministério da Educação, sob coordenação da UAB, onde instituições de reconhecida competência em educação presencial estabelecem parcerias com prefeituras e estados.

\section{Instrumentos}

Foi feita uma ficha de identificação do professor, caracterizando sua formação e trajetória profissional na EAD, e do aluno, reunindo dados pessoais e sociais, as motivações para escolha do curso e importância dada à carreira. Elaborou-se um roteiro de entrevista do professor, visando conhecer a experiência em docência com a população ribeirinha, a motivação e qualidade da interação entre professor e alunos, a relevância e visão crítica do trabalho; e um roteiro de entrevista do aluno, buscando conhecer os motivos da escolha do curso em licenciatura a distância, a qualidade da interação entre alunos, professores e tutores do curso, o impacto do curso na atuação profissional $\mathrm{e}$ as possibilidades de crescimento e reconhecimento pessoal e social. Finalmente, um roteiro de trabalho de campo norteou os passos da pesquisa, a rotina do campo e a logística da viagem, num projeto desenvolvido em até seis meses.

\section{Procedimento}

Viagem ao Polo Veneza de Marajó. A pesquisa envolveu viagem de barco de Belém à cidade de São Sebastião de Boa Vista, junto com uma professora e a coordenadora do curso, vivenciado as condições e experiências desse deslocamento, participando do longo trajeto que é feito pelos professores nos rios da Amazônia. O mergulho no campo permitiu conhecer o Polo, onde foram realizadas as entrevistas com os ex-alunos, andar pela cidade, conversar com os moradores e deslocar-se de barco entre ilhas, aproximando-se da realidade da população pesquisada. De volta a Belém, foram feitas as entrevistas com os professores. 


\section{Análise}

Os dados foram analisados por categorias de relevância dos sujeitos entrevistados, visando uma reflexão compreensiva da percepção de alunos e professores sobre a experiência de educação à distância. O estudo não prevê generalização dos resultados e sim uma discussão contextualizada do tema.

\section{Resultados}

\section{Entrevistas com alunos que con- cluíram à graduação}

Foram entrevistados sete ex-alunos, com média de idade de 34 anos, seis do sexo feminino e um masculino; quatro casados e três solteiros; cinco concluíram o curso de Ciências Naturais, com Habilitação em Biologia, e dois o de Licenciatura Plena em Pedagogia. Três atuavam no ensino como professor e vice-diretor, técnico em educação, e coordenação pedagógica; três na área de apoio, um era técnico de informática e dois auxiliares administrativos; e apenas um não estava trabalhando. Foi destacado pelos entrevistados que as atividades profissionais como técnico em educação, coordenador pedagógico e vice-diretor de escola foram conquistadas porque eles fizeram a graduação.

Todos os participantes afirmaram não ter condições de fazer um curso de 108 graduação presencial por falta de oportunidade no município de origem, pela distância de instituições de ensino superior, necessidade de trabalhar ou impossibilidade financeira de residir em outra cidade. De outro lado, seus pais não têm formação superior, a maioria tem o ensino fundamental completo ou incompleto e um pai e duas mães não são alfabetizados. Quatro participantes têm irmãos com formação superior, através de cursos a distância, em São Sebastião da Boa Vista ou em outro município do Marajó.

Para preservar a confidencialidade foi atribuído a cada ex-aluno o nome de uma fruta regional; são eles: Bacuri, Beribá, Castanha, Cupuaçu, Graviola, Sapotilha e Taperebá. A análise estabeleceu cinco pontos relevantes: o modo de funcionamento do curso; o desejo de fazer uma graduação e a dedicação pessoal em estudar; a importância da experiência para vida e os ganhos obtidos; a interação com os colegas; e a interação com os professores.

1) O funcionamento do curso. Na visão dos alunos, as graduações em Pedagogia e em Biologia não transcorreram como o previsto. De início, sempre havia aulas presenciais aos finais de semana, com apostilas impressas, elaboradas pelos professores. Porém, no decorrer dos cursos, os materiais impressos deixaram de chegar, e as aulas presenciais foram rareando, tornando essencial o uso da plataforma. A precariedade do acesso à internet, a diminuição da presença dos professores e as dificuldades em ter acesso a materiais de pesquisa, somavam-se à falta de livros e às dificuldades de conciliar trabalho, estudo, família e atividades domésticas. 
Segundo Simas e Lima (2013), na região amazônica existem peculiaridades como as longas distâncias, a baixa densidade demográfica e a baixa renda da população que dificultam o acesso aos serviços de internet, sendo poucos serviços oferecidos nas cidades do interior. A precariedade do sinal de internet contribui para o agravamento de um quadro de exclusão digital dos habitantes da região, cabendo aos estados buscarem soluções.

2) O desejo e a dedicação num curso de graduação. Entre motivos para fazer uma graduação, os participantes destacam o desejo de conhecer mais sobre o mundo, a natureza, a realidade que os rodeia, através do saber acadêmico dominante e ser respeitado socialmente. Os entrevistados foram unânimes em afirmar que se esforçaram muito, seja nas aulas presencias no Polo, ou estudando em casa; lendo os materiais, fazendo as atividades propostas e postando trabalhos nas plataformas.

Palloffe Pratt (2004) descrevem um perfil semelhante ao encontrado nos alunos aqui estudados: estudantes que buscam novas formas de aprender, motivados, disciplinados, com altas expectativas com relação a crescimento profissional, tendendo a ser mais velhos e a manifestar uma atitude mais séria em relação à sua formação, do que a média dos alunos de graduação.

3) Ganhos na formação superior. Os entrevistados viram aspectos positivos relacionados ao desenvolvimento profissional e pessoal e a mudanças de atitude frente à vida, assinalando o orgulho dos seus familiares com sua formação superior. Num dos casos, o entrevistado era primeiro de toda a família a cursar uma faculdade. Outros acreditavam que iriam abrir espaço para conseguir se tornar professor. Após a graduação, três revelaram vontade de continuar estudando, se aperfeiçoando, tendo ingressado numa pós-graduação a distância.

Bacuri relata aumento de salário por causa da graduação, novas atitudes frente ao meio ambiente, melhor interação com as pessoas e segurança para expressar suas ideias. Beribá e Cupuaçu tiveram ascensão funcional para o cargo de coordenadora pedagógica e técnica em educação. Castanha, Graviola, Sapotilha e Taperebá não ingressaram em trabalho na educação, mas alcançaram reconhecimento social, mais consciência em relação ao meio ambiente, aumento dos contatos sociais, o que pode trazer oportunidades profissionais: «Aquilo que eu aprendi é meu, não tem quem tire. Eu consegui, eu hoje sou uma pessoa formada. Muitos tentaram, nem todos tiveram essa oportunidade" (Castanha).

4) Interação com os colegas. O relacionamento com os colegas foi bom, num clima de camaradagem e ajuda mútua. Cupuaçu e Sapotilha consideraram que a união das turmas foi estimulada pelas dificuldades e pela escassez de recursos que enfrentaram. Os entrevistados relataram que sempre um procurava ajudar o outro, telefonando para passar 
informações, postando os trabalhos dos colegas que não tinham acesso à internet de casa; compartilhando material; formando grupos de estudos, com o objetivo de que todos concluírem juntos.

5) Interação com os professores. A presença do professor era vista como uma grande oportunidade de obter conhecimento. É consenso nas falas que os professores eram disponíveis, tanto nas aulas presenciais, quanto para responder a e-mails e atender a telefonemas dos alunos. As respostas dos entrevistados denotam que eles tinham uma grande expectativa em relação ao contato com aquele que vinha de fora, da capital, com títulos acadêmicos: "A gente percebe a diferença dos professores daqui e dos que vêm de fora, que são universitários. Eles são mais capacitados, a linguagem muda" (Sapotilha). A expressão "sugar" apareceu em várias falas, sendo enfatizado que a vinda dos professores era uma grande oportunidade para tirar dúvidas e aprender.

Para Freud (1910), a transferência acontece em todas as relações humanas. No processo de transferência, os desejos inconscientes relacionados aos primeiros vínculos se atualizam e são canalizados a novos objetos. Nesse sentido, dentro do contexto ensino-aprendizagem, podemos perceber um laço afetivo, muitas vezes intenso, na relação professor-aluno. Nas falas dos entrevistados há sentimentos

110 de admiração e gratidão em relação aos seus professores, desejo de se tornarem iguais a eles. A transferência existente na relação professor-aluno é imprescindível para que ocorra aprendizagem. Segundo Freire (2014), a postura do professor, também, é muito relevante, ele precisa estar receptivo e disponível para permitir a aproximação de seus alunos e, assim, gerar um vínculo positivo.

Torna-se importante salientar que o professor precisa se implicar com afeto para obter do aluno atenção, desempenho, criatividade, envolvimento. Porém, ao investir afeto no professor, o aluno passa a demandar muitas coisas - atenção, respostas e soluções. Para Silva (2006), lidar com as questões transferenciais no contexto educacional não é fácil, o sentimento de onipotência pode levar o professor a tentar atender a todas as demandas do aluno, algo impossível e incompatível com a situação ensino-aprendizagem.

\section{Entrevista com professores}

Foram realizadas entrevistas com duas professoras que ministraram aulas no curso EAD, no Polo Veneza do Marajó, ambas com formação em biologia: uma com mestrado em Educação em Ciências, e a outra em Ecologia Aquática e Aquicultura. As duas trabalham há quatro anos com EAD, atuando no Polo de SSBV, em outros polos e também no Instituto Federal do Pará. Ambas foram contratadas para a EAD por processo seletivo.

Na análise, cinco pontos foram considerados relevantes: descrição da experiência; a importância do material didático; visão sobre a EAD e dificuldades encontradas; 
relação com os alunos; e os ganhos da experiência como professora da EAD. Para preservar a confidencialidade, cada professora recebeu o nome de um fruto de palmeira da região; são eles: Açaí e Bacaba.

1) A experiência na EAD em SSBV. As duas professoras descrevem sua vivência profissional como "maravilhosa". A professora Bacaba destacou o grande interesse demonstrado pelos alunos e a professora Açaí salientou que os alunos tinham pronta resposta diante dos estímulos e participavam ativamente das aulas. As duas destacaram a viagem de barco como uma grande dificuldade. Bacaba precisou vencer o medo de viajar de barco, pois o sacolejo, a sensação de estar presa no ambiente a deixava nervosa. Outra dificuldade foi a precariedade da internet, sendo necessário adaptar as ferramentas que tinham para diminuir os prejuízos pelas falhas de internet.

A professora Açaí disse que outra dificuldade encontrada foi o número reduzido de idas dos professores ao Polo: em um curso que durava um semestre, o professor ia uma vez. Ela considera que eles deveriam ir pelo menos uma vez por mês. Segundo a professora, somente na disciplina orientação do trabalho de conclusão de curso foi autorizado que ela fosse três vezes ao Polo. Ela considera que foi o momento em que ficou mais próxima dos alunos, e houve um retorno muito positivo, eles apresentaram bons trabalhos de conclusão de curso.

2) Importância do material didático. O material didático é produzido pelo professor formador que organiza os artigos, os textos e elabora as atividades. A professora Açaí disse que, ao elaborar o material das suas disciplinas, procurava os textos mais atualizados e que abordassem a realidade dos alunos, valorizando temas regionais. Para isso, precisou pesquisar sobre a cidade e as características locais. Segundo Marín (2009), a perspectiva intercultural abre espaço para a revalorização dos saberes locais e cria condições para que esses sejam compartilhados.

$\mathrm{Na}$ forma como ambas relataram o preparo do material didático e da apresentação das atividades, parece ter havido uma preocupação com a adequação do conteúdo e o respeito à história e à realidade dos alunos, numa postura pedagógica que respeita a multiplicidade e a bagagem cultural dos estudantes. Com diz Gadotti (2000): "A ideia de aprender a partir dos conhecimentos que o indivíduo traz, a noção de ensinar a partir de temas geradores, a educação como ato de transformação social e politicidade da educação são apenas alguns legados deixados pela educação popular à pedagogia crítica universal" (p. 6).

3) A percepção da EAD e o manejo das dificuldades-ambas as professoras consideram que a EAD ajuda muito a democratizar o acesso à educação, tendo em vista que muitas cidades no estado do Pará não têm instituições de educação superior e, segundo Açaí, muitas não ofertam nem o ensino médio. Apesar das dificuldades decorrentes das falhas da internet e das poucas oportunidades de 
estar fisicamente no Polo, as professoras consideraram as relações estabelecidas com os alunos como satisfatórias, assim como os alunos descreveram a percepção de que os professores estavam abertos e disponíveis, atendendo a ligações telefônicas e respondendo a e-mails, sempre que eles os procuravam. De acordo com Sacco (2010), a EAD rompe com o princípio de que é necessário que professor e aluno estejam juntos no mesmo espaço e horário para que se dê a educação. As tecnologias e metodologias usadas permitem que o aprendizado aconteça mesmo sem o encontro físico de aluno e professor.

4) Percepção da relação professor-aluno. As professoras destacaram que os alunos tinham um grande interesse em aprender, que eram muito respeitosos e valorizavam o momento da aula. Ambas se envolveram bastante com os alunose se sentiam estimuladas a pesquisar mais e a se dedicar mais às turmas. Apontaram a experiência como oportunidade de melhoria de suas formações e de seus desempenhos profissionais: "Eles queriam aprender, estavam ansiosos por ter alguém lá, orientando, tirando dúvidas, perguntando, esclarecendo. $\mathrm{Eu}$ acredito que quem quer aprender a gente tem que dar a mão e ir junto, era uma turma que realmente queria" (Bacaba).

Pode ser observado na fala das professo-

112 ras que o desejo de aprender dos alunos foi um combustível importante também para o desejo delas - de ensinar e de buscar auto desenvolvimento profissio- nal. Como nos aponta Soares dos Santos (2009), na relação ensinar-aprender há necessidade de que seja estabelecido um vínculo de afeto, e de que aluno e professor estejam comprometidos com seus desejos, de tal forma que o desejo de um potencialize o desejo do outro, trazendo ganhos, tanto acadêmicos, quanto pessoais para ambos. Silva (2006), afirma que o ato de educar tem mais relação com o que o educador é, do que com aquilo que ele expressa. Dessa forma, quanto mais o educador se conhece e se implica, maiores serão a qualidade e a profundidade do processo de educação.

5) Os ganhos da experiência profissional na EAD. A professora Açaí destaca que a experiência com a EAD causou uma grande influência nos rumos de sua vida profissional, despertando o desejo de continuar os estudos. A professora Bacaba considera que a experiência com EAD fez com que percebesse que esse é um caminho viável para levar educação às pessoas que vivem em regiões mais isoladas, sendo uma ferramenta importante para o Pará, estado cortado por grandes rios, com difícil acesso por estradas.

Silva (2006) destaca que os educadores abertos ao relacionamento com seus alunos fazem trocas valiosas e também se transformam nessa relação. Essas trocas se dão internamente, tanto nos alunos quanto nos docentes. Nesse processo, o desejo e a dedicação de ambos, professor e aluno, gera desenvolvimento e transformação. 


\section{Discussão}

Durante as entrevistas, foi salientado que cerca de 300 jovens concluem o ensino médio, por ano, no município. Desses, nenhum tem a oportunidade de iniciar um curso superior na própria cidade. Isso porque os cursos que são oferecidos no Polo atendem prioritariamente professores e funcionários de estabelecimento de ensino. E, pelo que foi falado pelos entrevistados e observado durante o trabalho de campo, desde a formatura das turmas de Pedagogia e Biologia, que concluíram o curso em meados de 2014, não aconteceram novos cursos de graduação no Polo: "Eles ficarão sem estudar por falta de oportunidade. Vão ficar estagnados no tempo, esperando por 10, 20 anos para poder fazer o nível superior, como nós ficamos" (Cupuaçu).

A concentração de universidades públicas e privadas nas capitais e cidades de grande e médio porte dificultam a interiorização do ensino superior. Localidades como São Sebastião da Boa Vista e outras da região não têm população grande o suficiente para justificar o estabelecimento de uma instituição pública e não são atraentes, do ponto de vista financeiro, para as instituições particulares. Portanto, iniciativas como as de cursos EAD, através da UAB, são fundamentais para viabilizar o ensino superior a essas populações ribeirinhas e fomentar o desenvolvimento local e regional.

\section{Conclusão}

Como outras iniciativas no âmbito das políticas educacionais, na história do país, o programa da Universidade Aberta do Brasil também está perdendo força e deixando de cumprir sua nobre função - a de formar professores que atuam nas localidades mais distantes do país -, quando, na verdade, precisava ser ampliado, pois é a oportunidade de dar formação, através de universidades reconhecidas, a quem não teria condições de estudar por outros meios.

Esses são grandes entraves impostos pela realidade, das políticas e do sistema educacional brasileiro, aos desejos dos cidadãos de aprender e de progredir profissionalmente. Na oferta de cursos EAD, os alunos permanecem em suas cidades de origem e não se privam do contato com os professores, que vão até as cidades para as aulas presenciais, aproximando-se dos alunos e de suas realidades. Assim, os professores podem aproveitar a bagagem cultural dos alunos, adequar o conteúdo das disciplinas e respeitar os costumes, as linguagens e os valores da comunidade, ficando as aulas mais interessantes e com maior relevância para a prática profissional local.

O curso EAD no Polo São Sebastião de Boa Vista revelou-se uma modalidade de ensino viável para a região e, possivelmente, para outras tantas regiões de um país tão vasto e com tanta carência educacional como é o Brasil. Dessa forma, a educação a distancia é um vasto 
terreno para estudos e pesquisas, do ponto de vista pedagógico, econômico, do emprego de recursos tecnológicos e, sobretudo, dos impactos em nível profissional, pessoal e social.

\section{Referências}

Bogdan, R. C., Bïklen, S. K. (1994). Investigação qualitativa em educação: uma introdução à teoria e aos métodos. Portugal: Porto Editora.

Fórum Nacional de Educação [FNE] Educação brasileira: indicadores e desafios. Documento de Consulta. Recuperado 6 outubro 2014, de http:// conae 2014. mec.gov.br/images/pdf/edu cacaobrasileiraindicadoresedesafios.pdf

Freire, P. (2014). Pedagogia dos sonhos possíveis. São Paulo: Paz \& Terra.

Freud, S. (1996). Cinco Lições de Psicanálise. (17-66). Edição Standard Brasileira das Obras Completas de Sigmund Freud (vol. IX). Rio de Janeiro: Imago.

Gadotti, M. (2000). Perspectivas atuais da educação. São Paulo em Perspectiva, 14(2), 2000. Recuperado 7 julho 2015 , de www.scielo.br/pdf/spp/v14n2/9782. pdf

Guimarães de Mattos, C. L. (2011). A abordagem etnográfica na investigação científica. Recuperado 5 maio 2015 , de http://books.scielo.org/id/8fcfr/pdf/ mattos- 9788578791902-03.pdf

Instituto Brasileiro de Geografia e Estatística [IBGE] (s. d.). Recuperado 5 outubro 2014, de http://www.ibge. gov. br/home/ estatistica/economia/perfilunic/default. shtm
Instituto Nacional de Pesquisas Educacionais Anísio Teixeira [INEP] (s. d.). Censo de Educação Superior 2012. Recuperado 25 outubro 2015, de http://portal. inep.gov. br/visualizar/-/asset_publisher/6AhJ/ content/brasil-teve-mais-de-7 -milhoesde-matriculas-no-ano-passado

Marin, J. (2009). Interculturalidade e descolonização do saber: relações entre saber local e saber universal, no contexto da globalização. Visão Global, Joaçaba, 12(2), 127-154. Recuperado 25 outubro 2013, de http://editora. unoesc.edu.br/index.php/ visaoglobal/ viewFile/617/278

Ministério da Educação [MEC] (2014). Recuperado 5 outubro 2014, de http:// www.mec.gov.br

Minayo, M. C. S. (2001). Pesquisa social: teoria, método e criatividade. Petrópolis: Vozes.

Moreira, M. A. (1990). Pesquisa em ensino: o vê epistemológico de Gowin. São Paulo: EPU.

Moura, A. de. (2015). O acesso à graduação através da educação a distância: um estudo de caso em uma comunidade ribeirinha no interior do Estado do Pará (Dissertação de Mestrado). Rio de Janeiro, Universidade Veiga de Almeida.

Organização para a Cooperação e o Desenvolvimento Econômico [OCDE] (2014). Relatório. Education at a Glance 2014. Recuperado 28 maio 2015, de http://www.cnedu.pt/pt/noticias/ internacional/926-relatorio-da-ocdeeducation-at-a-glance-2014

Oliveira, J. A. (2004). A cultura nas (das) pequenas cidades da Amazônia Brasileira. Recuperado 5 maio 2015, de www. 
ces.uc.pt/lab2004/inscricao/pdfs/ painel74/JoseAldemirdeOliveira.pdf

Palloff, R. M. y Pratt, K. (2004). O aluno virtual: um guia para trabalhar com estudantes online. Porto Alegre: Artmed.

Preti, O. (2009). Educação a distância: fundamentos e políticas. Cuiabá: EdUFMT.

Sacco Dias, R. (2010). Ensino a distância e educação: imagem e corpo professoral (Dissertação de Mestrado). São Paulo, Universidade de São Paulo. 2010. Recuperado 23 setembro 2015, de http://www.teses.usp.br/teses/ disponiveis/48/48134/tde-30072010153550/pt-br.php

Silva, C. S. R. (2006). A relação dinâmica transferencial entre professor-aluno no ensino. Ciência e Cognição, 08, 165171. Recuperado 18 setembro 2015, de <www.cienciasecognicao.org/pdf/v.08/ m32696.pdf

Silva, R. F. B. y Talamoni, J. L. B. (2008). Uma experiência de investigação social no Baixo Amazonas. Revista Ciência em Extensão, 4(1),61. Recuperado 19 setembro 2015, de https://repositorio.unesp. br/bitstream/handle/11449/143360/ ISSN1679-4605-2008-04-01-52-61. pdf?sequence $=1$ \&isAllowed $=y$
Simas, D. S. y Lima, J. S. (2013). Desafios da inclusão digital no interior do Amazônas. Recuperado 1 outubro 2015, de www.coral.ufsm.br/congressodireito/ anais/2013/6-9.pdf

Soares dos Santos,J. M. (2009). A transferência no processo pedagógico: quando fenômenos subjetivos interferem na relação de ensinoaprendizagem. Recuperado 7 julho 2015, de www.bibliotecadigital.ufmg.br/ dsp ace/bitstream/handle/1843/ FAEC-84GTXZ/dissertacaojacia. pdf;jsessionid $=7$ B239A842F345FC 7A14082669? sequence $=1$

Souza, J. A. de. (2007). Políticas de acesso à educação superior: flexibilização e democratização do ingresso na universidade (Dissertação de Mestrado). Minas Gerais, Universidade Federal de Uberlândia. Recuperado 15 maio 2015, de https://repositorio.ufu. br/bitstream/123456789/14055/1/ JASouzaDISPRT.pdf Valente, J.A. y Moran, J.M. (2011). Educação a distância: pontos e contrapontos. São Paulo: Summus.

Waltenberg, F. D. (2005). Iniquidade Educacional no Brasil: uma avaliação com dados PISA 2000. Revista Econômica, 6(1), 67-118. 